\title{
Correction to: Investigation of electrical, magnetic, and optical properties of silver-substituted magnesium-manganese ferrite nanoparticles
}

\author{
Somnath $^{1} \cdot$ Khalid Mujasam Batoo ${ }^{2} \cdot$ Emad H. Raslan ${ }^{3} \cdot$ Syed Farooq Adil ${ }^{4} \cdot$ Indu Sharma $^{1} \cdot$ Gagan Kumar $^{5}$
}

Published online: 30 May 2020

(c) Springer Science+Business Media, LLC, part of Springer Nature 2020

\section{Correction to: \\ Journal of Materials Science: Materials in Electronics (2020) 31:7880-7888 \\ https://doi.org/10.1007/s10854-020-03326-6}

The original version of this article unfortunately contains an incorrect project number in Acknowledgment section. The correct acknowledgement text is given below.

Acknowledgements Author K.M. Batoo is thankful for the financial support to Researchers Supporting Project Number (RSP-2019/148), at King Saud University, Riyadh, Saudi Arabia.
Publisher's Note Springer Nature remains neutral with regard to jurisdictional claims in published maps and institutional affiliations.

The original article can be found online at https://doi.org/10.1007/ s10854-020-03326-6.

Gagan Kumar

physics.bhargava@gmail.com

1 Department of Physics, Career Point University, Hamirpur, India

2 King Abdullah Institute for Nanotechnology, King Saud University, P. O. Box 2455, Riyadh 11451, Saudi Arabia

3 Department of Physics and Astronomy, College of Science, King Saud University, P. O. Box 2455, Riyadh 11451, Saudi Arabia

4 Department of Chemistry, College of Science, King Saud University, P. O. Box 2455, Riyadh 11451, Saudi Arabia

5 Department of Physics, Chandigarh University, Gharuan, Mohali, Punjab, India 